\title{
(U]
}

Revista Mexicana de Derecho Constitucional Núm. 33, julio-diciembre 2015

\section{ANÁLISIS DE LA LEY FEDERAL DE RESPONSABILIDAD PATRIMONIAL DEL ESTADO Y DE LA LEY GENERAL DE VÍCTIMAS: DESAFÍOS Y OPORTUNIDADES DE UN RÉGIMEN EN CONSTRUCCIÓN}

\author{
ANALYSIS OF FEDERAL LIABILITY OF THE STATE AND GENERAL \\ THE VICTIMS LAWS: CHALLENGES AND OPPORTUNITIES \\ OF A SYSTEM IN CONSTRUCTION
}

\section{Magda Zulema MosRi GUTIÉRREZ*}

RESUMEN: En la actualidad, ningún Estado democrático puede dejar de asumir sus responsabilidades. Algunos tratados internacionales obligan a sus Estados miembros a adoptar mecanismos internos para reparar los daños que causen a los bienes y derechos de los particulares. Desde 2002, México incorporó a su sistema jurídico la responsabilidad "objetiva y directa" como mecanismo para indemnizar a los particulares por los daños causados por la actividad administrativa irregular del Estado. Sin embargo, este esquema, surgido del párrafo segundo del artículo 113 constitucional y de su ley reglamentaria, mantiene algunas restricciones en su instrumentación que, con la adopción del nuevo paradigma en materia de derechos humanos por el Estado mexicano mediante la reforma constitucional de 2011, hacen necesario replantear su instrumentación, sobre todo, a partir de la publicación de la Ley General de Víctimas en 2013, la cual ofrece a los particulares medidas de reparación adicionales para los casos en que hayan sufrido un daño o puesta en peligro de sus bienes jurídicos o derechos como consecuencia de la comisión de un delito o de violaciones a sus derechos humanos.

Palabras clave: responsabilidad patrimonial del Estado, actividad administrativa irregular, responsabilidad objetiva y directa, indemnización, daño, reparación integral, derechos humanos.
ABSTRACT: Nowadays, the democratic state is assuming a new scope of responsibilities. Some International treaties in forced the Member States to adopt internal mechanisms to repair damages caused to the property and rights of individuals. Since 2002, Mexico incorporated to its legal system the "objective and direct" responsibility as a mechanism to indemnify individuals for damages caused by irregular administrative activities of the government and the State. However, this scheme arising from the second paragraph of Article 113 of the Constitution and their regulatory law, maintains some restrictions on its implementation with the adoption of the new paradigm in the field of human rights by the Mexican State through constitutional reform of 2011, make it necessary to revise its implementation, especially since the publication of the General Victims Act in 2013. This law provides additional repair specific measures for cases that have suffered damage or danger to their properties or rights as a result of crime or violations of their human rights.

Descriptors: State liability, irregular administrative activity, objective and direct responsibility, indemnification, damage, integral reparation, human rights.

* Magistrada en la Sala Superior del Tribunal Federal de Justicia Fiscal y Administrativa. 


\section{INTRODUCCIÓN}

El 14 de junio de 2002 se reformó el artículo 113 de la Constitución Política mexicana para incorporar a su segundo párrafo el régimen de responsabilidad "objetiva y directa" del Estado, procedente por los daños que cause a los particulares por su actividad administrativa irregular. ${ }^{1}$

Antes de esta reforma constitucional, la responsabilidad patrimonial del Estado se regía por la legislación civil, salvo algunas excepciones administrativas - como la expropiación por causa de utilidad pública o lo previsto en la Ley de Depuración de Créditos a cargo del Gobierno Federal de 1941 - bajo un esquema de responsabilidad subjetiva y subsidiaria (indirecta), conforme a lo siguiente:

a) Responsabilidad subjetiva: el particular tenía que demostrar, en un procedimiento administrativo o jurisdiccional, la negligencia, dolo o culpa del servidor público responsable de la actividad que le había causado daño, para exigir una indemnización.

b) Responsabilidad subsidiaria: si al concluir el procedimiento administrativo o jurisdiccional correspondiente, se demostraba la responsabilidad del servidor público imputado y se le condenaba a reparar los daños, pero éste no tenía recursos suficientes para cubrir el monto de la indemnización o sólo podía pagar una parte, correspondía al Estado cubrir el importe faltante o el total de la indemnización, dejando a salvo sus derechos para, en otro momento, repetir contra el servidor público responsable.

Para el doctor Álvaro Castro Estrada, la responsabilidad directa es aquella que se imputa a la administración pública federal, sin que sea necesario - como requisito previo - obtener la identificación o demandar al servidor público agente de la misma, en oposición a la responsabilidad indirecta, en la cual se debe precisar al agente que por su actuar culposo, doloso o negligente es responsable frente al particular lesionado. ${ }^{2}$

1 El 27 de mayo de 2015 se publicaron en el Diario Oficial de la Federación las reformas constitucionales que dieron origen al Sistema Nacional Anticorrupción, lo cual motivó que el segundo párrafo del artículo 113 de la Constitución Política mexicana se incorporara al final del artículo 109 de la carta magna.

2 Castro Estrada, Álvaro, Responsabilidad patrimonial del Estado, 2a. ed., México, Porrúa, 2000, p. 46. 
La responsabilidad objetiva o sin culpa es aquella que descansa en la teoría civil del riesgo, en la cual, cuando una persona crea un riesgo es responsable por los posibles daños que su actividad — aun siendo lícita - genere, ya que la responsabilidad sobreviene, a decir de la maestra Julieta Ovalle Piedra, simplemente por causar un daño, es decir, de un hecho material. ${ }^{3}$ Por ello, en la responsabilidad objetiva, la relación causal no es física sino legal o presuntiva, como menciona el doctor Ignacio Galindo Garfias:

No se trata de la causalidad física sino de la causalidad legal o presuntiva que el derecho establece a cargo de la persona que ha creado el riesgo. Es suficiente que exista la posibilidad de que el daño pudo racionalmente haberse producido por la cosa peligrosa; es decir que la víctima se encontraba en "zona de riesgo" para que surja la obligación de reparar el daño sufrido. ${ }^{4}$

La responsabilidad objetiva proviene de la naturaleza misma de la actividad que realiza la persona, en tanto que la responsabilidad subjetiva deriva de la conducta omisa, negligente o descuidada de ésta. ${ }^{5}$

No obstante, así la defina o califique la Constitución como “objetiva y directa", por la redacción de la reforma al artículo 113 constitucional, el esquema de responsabilidad del Estado por los daños causados en los bienes y derechos de los particulares, no puede considerarse objetiva y directa en sentido estricto - ya que se restringe el ámbito material de la actividad por la que se puede responsabilizar al Estado, a únicamente su "actividad administrativa irregular", eliminando los daños generados por su actuación lícita, que como se ha señalado, en la teoría del riesgo es suficiente para la determinación de responsabilidades.

Con la reforma (de 2002) al artículo 113 de la Constitución, se llevó a nivel constitucional la responsabilidad "objetiva y directa"; la cual —ya se dijo - no requiere que la actividad causante del daño sea calificada como dolosa, porque se apoya en la teoría del riesgo y no en la teoría de la culpa, ni de agotar un procedimiento previo - administrativo o judicial — para determinar la responsabilidad de un agente, en este caso de un servidor

3 Ovalle Piedra, Julieta, La responsabilidad civil por productos en México, Canadá y Estados Unidos, México, UNAM, Instituto de Investigaciones Jurídicas, 2001, p. 23, http://biblio.juridicas.unam.mx/libros/1/32/3.pdf.

4 Galindo Garfias, Ignacio, http://www.juridicas.unam.mx/publica/librev/rev/revd priv/cont/3/jur/jur15.pdf.

5 Idem. 
público. Sin embargo, como se explicará más adelante, en México, la responsabilidad patrimonial del Estado presenta particularidades distintas a lo que en la doctrina se conoce como responsabilidad objetiva y directa, las cuales impactan el derecho a indemnización que de ésta deriva.

A partir de las sentencias de la Corte Interamericana de Derechos $\mathrm{Hu}$ manos que condenaron a nuestro país "González y Otras (Campo Algodonero) vs. México" y "Radilla Pacheco vs. Estados Unidos Mexicanos"7 y de la agenda pública impulsada por la sociedad civil contra la violencia en México - principalmente en el sexenio pasado- se emitió la Ley General de Víctimas, disposición que reconoce y garantiza los derechos de las víctimas del delito y de violaciones a derechos humanos; y que también prevé medidas de restitución, rehabilitación, compensación, satisfacción y garantías de no repetición, a cargo del Estado y a favor de las víctimas - quienes acrediten en los términos de dicha Ley, el daño o menoscabo de sus derechos - en sus dimensiones individual, colectiva, material, moral y simbólica, para que éstas sean reparadas de manera integral, adecuada, transformadora y efectiva.

Lo anterior, en congruencia con la reforma constitucional del 10 de junio de 2011, sobre derechos humanos, mediante la cual México reconoció como obligaciones a cargo del Estado: prevenir, investigar, sancionar y reparar las violaciones a los derechos humanos, en los términos de ley.

La consolidación del régimen político democrático y la sociedad cada vez más participativa han abierto el debate en torno al derecho de indemnización, previsto en la Ley Federal de Responsabilidad Patrimonial del Estado y su aplicación, para aquellos casos en que los daños a los particulares se producen por actividades del Estado que no pertenecen a su esfera administrativa, particularmente frente a su actividad judicial. Sin embargo, la compensación, medida pecuniaria dispuesta en la Ley General de Víctimas, sí prevé en sus supuestos de aplicación al error judicial.

Sobre este tema, en las líneas siguientes se expondrán las características principales de los regímenes de responsabilidad del Estado, previstos en la Ley Federal de Responsabilidad Patrimonial del Estado y la Ley General de Víctimas y sus esquemas de reparación de daños.

Es importante mencionar que hay otras modalidades de reparación del daño, como las previstas en los artículos 6o. de la Ley Federal del Proce-

6 Corte Interamericana de Derechos Humanos, 16 de noviembre de 2009.

7 Corte Interamericana de Derechos Humanos, 23 de noviembre de 2009. 
dimiento Contencioso Administrativo y 34 de la Ley del Sistema de Administración Tributaria (SAT), las cuales permiten condenar a las autoridades a pagar indemnizaciones por daños y perjuicios causados a particulares, sin embargo, no serán motivo de análisis en el presente, ${ }^{8}$ en atención de su naturaleza, específicamente contenciosa.

\section{LA RESPONSABILIDAD PATRIMONIAL DEL ESTADO POR SU ACTIVIDAD ADMINISTRATIVA IRREGULAR}

En México, originalmente se propuso a los diputados y senadores la adopción de la teoría de la responsabilidad directa y objetiva. Sin embargo, los legisladores determinaron acotar su procedencia y restringir el derecho a la indemnización para aquellos daños derivados —únicamente - de la "actividad administrativa irregular" del Estado, como se desprende de lo mencionado en el dictamen de primera lectura del "Decreto por el que se modifica la Denominación del Título Cuarto y se adiciona un segundo párrafo al artículo 113 de la Constitución Política de los Estados Unidos Mexicanos", presentado en la sesión del 6 de noviembre de 2001 del Senado de la República. ${ }^{9}$

8 El artículo 6o. de la Ley Federal del Procedimiento Contencioso Administrativo prevé que "la autoridad demandada deberá indemnizar al particular afectado... cuando la unidad administrativa de dicho órgano cometa falta grave al dictar la resolución impugnada y no se allane al contestar la demanda en el concepto de impugnación de que se trata. Habrá falta grave cuando: I. Se anule por ausencia de fundamentación o de motivación, en cuanto al fondo o a la competencia. II. Sea contraria a una jurisprudencia de la Suprema Corte de Justicia de la Nación en materia de legalidad. Si la jurisprudencia se publica con posterioridad a la contestación no hay falta grave. III. Se anule con fundamento en el artículo 51, fracción V de esta Ley [cuando la resolución administrativa dictada en ejercicio de facultades discrecionales no corresponda a los fines para los cuales la ley confiera dichas facultades]. La condenación en costas o la indemnización establecidas en los párrafos segundo y tercero de este artículo se reclamará a través del incidente respectivo, el que se tramitará conforme lo previsto por el cuarto párrafo del artículo 39 de esta Ley".

9 En 1999, las principales fuerzas políticas del país presentaron dos iniciativas para instituir a nivel constitucional, la responsabilidad patrimonial del Estado: el Partido Revolucionario Institucional (PRI) y el Partido Acción Nacional (PAN). El PRI promovió una iniciativa de decreto para modificar la denominación del título cuarto y adicionar un segundo párrafo al artículo 113 de la Constitución Política de los Estados Unidos Mexicanos, en materia de responsabilidad patrimonial del Estado. Asimismo, el grupo parlamentario del PAN en la Cámara de Diputados presentó el 16 de junio de 1999 una iniciativa para adicionar un duodécimo párrafo al artículo 16, un segundo párrafo al artículo 113, 
Respecto a los alcances de la responsabilidad objetiva y directa que se planteaban con esta reforma al artículo 113, en el Dictamen del decreto de esta iniciativa, presentado al Senado, se destaca lo siguiente:

El sistema que se establecerá en México permitirá que la responsabilidad a fincar cuente con dos importantes características: ser objetiva y directa.

Será directa, en virtud de que la administración no responderá subsidiariamente por el servidor público relacionado con el daño, sino que podrá exigirse al Estado de manera inmediata la reparación del mismo, por supuesto, dejando a salvo el derecho de repetición en contra del funcionario por parte de la autoridad.

En cuanto a la responsabilidad objetiva, con ella nos referimos a que, ajena a la responsabilidad subjetiva, no dependerá de un actuar doloso o ilegal de un funcionario en particular.

Cabe aclarar que la actividad que pudiera resultar dañosa, será aquella que guarde el carácter de administrativa, tomando en cuenta que un aspecto central de la responsabilidad del Estado es la responsabilidad patrimonial de la Administración Pública. Al respecto, la Colegisladora ha argumentado que, en efecto, la tarea que podría resultar mayormente dañosa por la magnitud y cantidad de los actos que desarrolla, es la administrativa, además de que la figura de la responsabilidad se ha ubicado y avanzado preferentemente en el ámbito del derecho administrativo, debido a que se hace recaer sobre los actos que producen efectos singulares y tienen como finalidad la aplicación de una ley.

Por ello, aunque no se niega la posibilidad de causación de algún daño por parte de los poderes legislativo y judicial, por lo incipiente del tema y posibles consecuencias no deseables, éstos quedan excluidos por el momento de la responsabilidad patrimonial. Este criterio será el que prevalezca, en tanto la evolución en la experiencia jurídica y la doctrina sobre el particular proporcionen los elementos para ampliar la responsabilidad de los demás órganos del Estado.

No pasa inadvertido a esta comisión, el hecho de que en el dictamen elaborado por la Cámara de Diputados se haya precisado que "El alcance

una fracción VIII al artículo 116, un segundo párrafo a la base quinta, apartado C, del artículo 122 de la Constitución Política de los Estados Unidos Mexicanos, y modificar la denominación del título cuarto de la misma. El 28 de abril de 2000 se dictaminaron las dos iniciativas en sentido aprobatorio, acerca de la institución de la responsabilidad patrimonial del Estado en el texto constitucional, y un día después se aprobó por el pleno de la Cámara de Diputados; más tarde se remitió a la Cámara de Senadores, para su aprobación, lo que ocurriría el 8 de noviembre de 2001 . 
de la responsabilidad del Estado se circunscribe a la lesividad de su actividad administrativa irregular". Dicha precisión es relevante, pues de esta manera se logra conjugar en forma por demás atinada la noción de "daños" y el concepto de "responsabilidad objetiva y directa".

Lo anterior supone que siempre que la actividad del Estado cause daño a los particulares, se estará en presencia de una actividad administrativa irregular; porque lo irregular en materia de responsabilidad objetiva, es la producción del daño en sí mismo. En este sentido, no puede calificarse como regular una actividad administrativa que como tal, cause daños a los particulares o gobernados.

No se considera prudente, por el momento, incluir la actividad normal o regular de la administración, dado que ése criterio no ha cobrado gran aceptación en nuestro derecho; sin perjuicio por supuesto, de que el rumbo que tomen estas nuevas disposiciones permitan una revisión posterior sobre este punto.

Como consecuencia del actuar irregular mencionado, surgirá la obligación a cargo de la Administración de indemnizar para restaurar la integridad del patrimonio afectado. Este patrimonio lesionado, de acuerdo a la más explorada doctrina, deberá ser susceptible de individualización con relación a una persona o grupo de personas. ${ }^{10}$

Como se puede ver, la responsabilidad patrimonial del Estado en México bajo este esquema, objetiva y directa — sui generis—, fue el primer paso de un sistema en consolidación que a diez años, y a la luz de las reformas constitucionales en materia de derechos humanos, requiere una actualización conforme a la nueva realidad nacional y al principio pro homine.

Respecto a la restricción con que opera el sistema de responsabilidad patrimonial del Estado del artículo 113 constitucional, la Segunda Sala de la Suprema Corte de Justicia de la Nación ha manifestado mediante tesis que:

De la razón legislativa que dio lugar a la adición al artículo 113 de la Constitución Política de los Estados Unidos Mexicanos, publicada en el Diario Oficial de la Federación el 14 de junio de 2002, se advierte que la intención expresa del Poder Revisor de la Constitución fue limitar la responsabilidad patrimonial del Estado únicamente al daño que produzca con motivo de su

10 Dictamen del "Decreto por el que se modifica la denominación del título cuarto y se adiciona un segundo párrafo al artículo 113 de la Constitución Política de los Estados Unidos Mexicanos", Diario de los Debates (22), Cámara de Senadores, LXVIII, año II, primer periodo ordinario, 6 de noviembre de 2001. 
"actividad administrativa irregular", por ende, si bien se aceptó esta delimitación podría ser sujeta de revisión posterior con base en el desarrollo que tuviere la regulación de responsabilidad patrimonial en nuestro país, lo cierto es que extender su ámbito protector para incluir los actos normales o regulares de la administración pública, sólo puede tener efecto a virtud de reforma constitucional, por lo que esa ampliación protectora no puede implementarse mediante la ley reglamentaria $u$ otras normas secundarias, pues indubitablemente se contravendría la esencia que inspiró esta reforma constitucional. ${ }^{11}$

Es importante recordar que sólo habla de responsabilidad objetiva del Estado cuando éste responde frente a cualquier daño provocado por su actividad, ya sea ilícita o no; responsabilidad que se puede llamar directa cuando los particulares afectados no necesitan agotar procedimientos previos para acreditar la culpa o el dolo de un agente, que en este caso tendría que recaer en un servidor público o en una institución gubernamental.

De acuerdo con la reforma al artículo 113 constitucional y la Ley Federal de Responsabilidad Patrimonial del Estado, en México, el Estado responderá patrimonialmente sólo por los daños causados por su actividad materialmente administrativa cuando ésta sea irregular y no por cualquier daño, como lo indica la teoría de la responsabilidad objetiva.

En la Ley Federal de Responsabilidad Patrimonial del Estado, publicada en el Diario Oficial de la Federación (DOF) el 31 de diciembre de 2004, se definió como actividad administrativa irregular aquella "que cause daño a los bienes y derechos de particulares que no tengan obligación jurídica de soportarlo, en virtud de la inexistencia de fundamento legal o causa jurídica de justificación que legitime el daño de que se trate". ${ }^{12}$

Es decir, que la responsabilidad patrimonial del Estado mexicano es directa, en tanto que no se requiere acreditar la culpa o dolo de los servidores públicos que ejecutaron el acto lesivo para solicitar una indemnización. No obstante, en el artículo 18 de la Ley Federal de Responsabilidad Patrimonial del Estado, se prevé que los particulares en su demanda señalen al servidor o servidores públicos involucrados en la actividad administrativa irregular.

Lo anterior, aparentemente contraviene el segundo párrafo del artículo 113 constitucional, que libera a los particulares de la necesidad de ser los

11 Tesis 2a./J. 99/2014, Semanario Judicial de la Federación, Décima Época, libro 13, t. I, 13 de diciembre de 2014, p. 297.

12 Artículo 1o. de la Ley Federal de Responsabilidad Patrimonial del Estado, Diario Oficial de la Federación, 31 de diciembre de 2004. 
que deban acreditar la responsabilidad de los servidores públicos —al reconocer la responsabilidad como objetiva y directa - sobre todo, porque en la mayoría de los casos, los particulares no conocen a detalle el entramado organizacional y de mando de las instituciones, dependencias y entidades gubernamentales.

En el mismo sentido se ha pronunciado la Primera Sala de la Suprema Corte de Justicia de la Nación mediante tesis publicada el 25 de abril de 2014, en el Semanario Judicial de la Federación y la cual, en lo sustancial, señala lo siguiente:

RESPONSABILIDAD PATRIMONIAL DEL ESTADO. REQUISITOS PARA QUE PROCEDA

Toda vez que el término "responsabilidad objetiva" que prevé la Constitución, no puede ser entendido en el sentido que se le atribuye a la responsabilidad objetiva civil, sino que refiere a una responsabilidad derivada de un acto irregular del Estado, deben trasladarse los requisitos propios de la responsabilidad civil al esquema de responsabilidad patrimonial del Estado, sin ser necesario probar la culpa de un agente del Estado en particular, sino la actuación irregular de la dependencia demandada. Así, para que proceda el pago indemnizatorio por la actividad irregular del Estado, deben concurrir los siguientes requisitos: 1) La existencia de un daño. Dicho daño debe ser efectivo, evaluable económicamente e individualizado en relación con una o varias personas. 2) Que el daño sea imputable a la Administración Pública, por ser efecto de su actividad administrativa irregular, la cual puede consistir en la prestación deficiente del servicio público de salud. 3) El nexo causal entre el daño y la actividad de la Administración Pública. ${ }^{13}$

En términos de la jurisprudencia en comento, se ratifica que el particular no tiene la obligación de acreditar el grado de intervención de la voluntad del servidor público que participó en la actividad administrativa; sin embargo, ello no implica que el particular carezca de cargas probatorias; en efecto, debe probar en el procedimiento administrativo o en el juicio los elementos siguientes: 1) actividad, 2) la lesión (daño como afectación), y 3) el nexo causal entre la actividad y la lesión.

13 Tesis 1a. CLXXI/2014, Semanario Judicial de la Federación, Décima Época, libro 5, t. I, 5 de abril de 2014, p. 820. 
Ahora bien, el factor determinante de una actividad administrativa irregular consiste en que no exista para el particular la obligación jurídica de soportar la lesión.

En cambio, la actividad administrativa regular se puede configurar en las formas siguientes: 1) no causa daño, o 2) causa daño, pero el particular tiene el deber jurídico de soportarlo.

Esto confirma que el régimen de responsabilidad patrimonial no es totalmente objetivo, pues si lo fuera, se configuraría la obligación de indemnización del Estado sólo con la existencia de la lesión (daño) y su relación de causalidad con la actividad administrativa.

Porque si bien, como se ha dicho, la responsabilidad objetiva del Estado es procedente contra cualquiera de sus actividades sean regulares o irregulares. Ése no fue el espíritu de nuestra reforma — por eso la aparente contradicción - , ya que en el dictamen de la reforma al artículo 113 constitucional, que da origen a la Ley Federal de Responsabilidad Patrimonial del Estado, se puede leer:

Será necesario demostrar el vínculo de causalidad entre el actuar de la administración y sus servidores públicos, en ejercicio de su potestad como agentes de la misma, con el resultado dañoso. Esto no implica que la falta de individualización de la conducta e identificación del funcionario relacionado impida demostrar la conducta irregular de la administración, siempre y cuando la titularidad de la actividad o servicio que produjo el daño, pueda ser atribuida al Estado. ${ }^{14}$

Es por ello que en la Ley Federal de Responsabilidad Patrimonial del Estado se prevé que la responsabilidad patrimonial del Estado en México está condicionada a dos supuestos:

a) A la esfera administrativa de los tres poderes del Estado (Legislativo, Ejecutivo y Judicial), organismos constitucionalmente autónomos, dependencias y entidades de la administración pública federal, la Procuraduría General de la República, los tribunales federales administrativos y cualquier otro ente público de carácter federal. ${ }^{15}$

14 Dictamen del "Decreto por el que se modifica la denominación del título cuarto...", cit.

15 Artículo 2o. de la Ley Federal de Responsabilidad Patrimonial del Estado. 
b) A que la actividad administrativa lesiva carezca de fundamento legal o causa jurídica de justificación legítima.

Es decir, la responsabilidad del Estado, a que hace referencia el segundo párrafo del 113 constitucional y la Ley Federal de Responsabilidad Patrimonial del Estado, está restringida a la materia administrativa — actos materialmente administrativos - y sólo procede cuando esta actividad administrativa se desplegó en contravención de la ley o injustificadamente: irregular.

En esta tesitura, es necesario tener en cuenta las acotaciones que efectuó el Pleno de la Suprema Corte de Justicia de la Nación al resolver las acciones de inconstitucionalidad 4/2004 y 121/2008, así como la tesis de jurisprudencia 2a./J. 99/2014.

De acuerdo con el artículo 4o. de la Ley Federal de Responsabilidad Patrimonial del Estado para solicitar una indemnización, se deben definir los supuestos siguientes:

1. La existencia del acto lesivo;

2. Que los daños y perjuicios materiales, personales y/o morales reclamados sean cuantificables o evaluables en dinero, $y$

3. Que los daños se relacionen directamente con una o varias personas y que sean desiguales a los que pudieran afectar al común de la población.

No obstante, éstos no son los únicos elementos que deben considerarse para determinar la procedencia de la indemnización - en términos de la Ley Federal de Responsabilidad Patrimonial del Estado-, sino que también deben quedar debidamente acreditadas: a) la existencia de la relación de causalidad entre la actividad administrativa y la lesión producida y b) la irregularidad de la actividad administrativa lesiva. ${ }^{16}$

Insiste en lo anterior, el artículo 50-A de la Ley Federal de Procedimiento Contencioso Administrativo, al señalar que las sentencias que dicte el Tribunal Federal de Justicia Fiscal y Administrativa, por las demandas que prevé la Ley Federal de Responsabilidad Patrimonial del Estado, deben contener como elementos mínimos los siguientes:

16 Artículos 1o., 18 y 23 de la Ley Federal de Responsabilidad Patrimonial del Estado. 
1. El relativo a que haya una relación de causalidad entre la actividad administrativa y la lesión producida, y la valoración del daño o perjuicio causado;

2. Determinar el monto de la indemnización, explicitando los criterios utilizados para su cuantificación, y

3. En los casos de concurrencia previstos en el capítulo IV de la Ley Federal de Responsabilidad Patrimonial del Estado, se deberán razonar los criterios de impugnación y la graduación correspondiente para su aplicación a cada caso en particular.

De acuerdo con la Ley Federal de Responsabilidad Patrimonial del Estado, la solicitud de indemnización debe dirigirse, en un primer momento, a la autoridad a quien se imputa el "acto lesivo", y una vez que ésta niegue la indemnización u otorgue un monto que el promovente considere insuficiente para resarcir el daño sufrido, podrá interponer el recurso de revisión, o bien, acudir ante el Tribunal Federal de Justicia Fiscal y Administrativa para que analice la respuesta de la autoridad involucrada y resuelva; lo cual también se prevé en el artículo 14, fracción VIII, de la ley orgánica de este último. ${ }^{17}$

Si bien este régimen de responsabilidad permite a los particulares solicitar al Estado que responda por su actividad administrativa irregular mediante el pago de una indemnización, correspondiente a la reparación integral del daño, y en su caso, del daño personal y moral; lo cierto es que al analizar sistemáticamente el texto de la Ley Federal de Responsabilidad Patrimonial del Estado, se advierte que —en esencia - sus mecanismos de reparación están orientados — principalmente - a daños patrimoniales. ${ }^{18}$

La insuficiencia de recursos presupuestales para el pago de las indemnizaciones a las que son condenadas las dependencias, entidades o instituciones responsables de la actividad administrativa irregular, suele ser uno de los puntos que impactan a esta figura - y cualquier otra - de reparación patrimonial, debido a que las dependencias involucradas deben tener un monto presupuestal para pagar estos compromisos, de lo contrario, se comprometería el funcionamiento de éstas al pago de las indemnizaciones. No obstante, deben generar las economías necesarias para cubrir estos adeudos y solicitar suficiencias presupuestarias en los ejercicios fiscales subsecuentes, razón por la cual —en apariencia - la insuficiencia presupuestal no

17 Artículos 17, 18 y 19 de la Ley Federal de Responsabilidad Patrimonial del Estado.

18 Artículo 12 de la Ley Federal de Responsabilidad Patrimonial del Estado. 
debería constituir un argumento que justifique demoras o desacatos en el pago de indemnizaciones.

Este régimen de responsabilidad del Estado pretende fungir como mecanismo de control de la actuación de los servidores públicos, al permitir que el Estado repita contra quienes sean responsables de la actividad administrativa irregular que haya dado lugar al pago de una indemnización.

Es importante destacar que la modificación al artículo 113 constitucional y su ley reglamentaria — que dan origen a este régimen de responsabilidad - fueron adoptadas por el legislador con anterioridad a la reforma de la Constitución en materia de derechos humanos, mediante la cual se incorporaron: el principio pro personae y la interpretación conforme, por lo que el tipo de reparación a la que hace referencia, y califica de integral, no consideraba los criterios emitidos por la Corte Interamericana de Derechos Humanos en este tema, lo cual sí hace el régimen de reparación de la Ley General de Víctimas.

La Corte Interamericana de Derechos Humanos ha señalado que

la reparación del daño ocasionado por la infracción de una obligación internacional requiere, siempre que sea posible, la plena restitución o restitutio in integrum, la cual consiste en el restablecimiento de la situación anterior. De no ser esto posible, cabe al tribunal internacional determinar una serie de medidas para, además de garantizar los derechos conculcados, reparar las consecuencias que las infracciones produjeron, así como establecer el pago de una indemnización como compensación por los daños ocasionados. Es necesario añadir las medidas de carácter positivo que el Estado debe adoptar para asegurar que no se repitan hechos lesivos... Las reparaciones son medidas que tienen a hacer desaparecer los efectos de las violaciones cometidas. Su naturaleza y su monto dependen de las características de la violación y del daño ocasionado en los planos material e inmaterial. No pueden implicar enriquecimiento ni empobrecimiento para la víctima o sus sucesores, y deben guardar relación con las violaciones declaradas en la sentencia. ${ }^{19}$

Es decir, que el esquema de responsabilidad del Estado descrito deberá ajustarse al modelo general de control de constitucionalidad que deriva del análisis sistemático de la reforma constitucional en materia de derechos humanos de junio de 2011.

19 Corte Interamericana de Derechos Humanos, caso Baldeón García vs. Perú, sentencia de 6 de abril de 2006. 


\author{
III. LA RESPONSABILIDAD DEL ESTADO POR DAÑOS \\ QUE SON CONSECUENCIA DE LA COMISIÓN DE UN DELITO \\ O VIOLACIONES DE DERECHOS HUMANOS
}

E1 10 de junio de 2011 se reformó la Constitución Política de los Estados Unidos Mexicanos, para incorporar los derechos humanos reconocidos en los tratados internacionales en los que el Estado mexicano es parte y las garantías para su protección.

Una de las principales modificaciones se hizo al artículo 1o. constitucional, conforme a lo siguiente:

Artículo 1o. En los Estados Unidos Mexicanos todas las personas gozarán de los derechos humanos reconocidos en esta Constitución y en los tratados internacionales de los que el Estado Mexicano sea parte, así como de las garantías para su protección, cuyo ejercicio no podrá restringirse ni suspenderse, salvo en los casos y bajo las condiciones que esta Constitución establece.

Las normas relativas a los derechos humanos se interpretarán de conformidad con esta Constitución y con los tratados internacionales de la materia favoreciendo en todo tiempo a las personas la protección más amplia.

Todas las autoridades, en el ámbito de sus competencias, tienen la obligación de promover, respetar, proteger y garantizar los derechos humanos de conformidad con los principios de universalidad, interdependencia, indivisibilidad y progresividad. En consecuencia, el Estado deberá prevenir, investigar, sancionar y reparar las violaciones a los derechos humanos, en los términos que establezca la ley.

Está prohibida la esclavitud en los Estados Unidos Mexicanos. Los esclavos del extranjero que entren al territorio nacional alcanzarán, por este solo hecho, su libertad y la protección de las leyes.

Como se puede ver, al segundo párrafo del artículo 1o. de la carta magna, se incorporó la interpretación conforme y el principio pro personae como metodología interpretativa de las normas relativas a los derechos humanos.

La interpretación conforme consiste en optar, en la interpretación de una norma secundaria que sea oscura o admita más de dos entendimientos posibles, por aquélla de la que derive un resultado acorde o en armonía con el texto constitucional. Este principio busca preservar la constitucionalidad 
de la norma impugnada y garantizar la supremacía constitucional y el principio de seguridad jurídica. ${ }^{20}$

Por su parte, el principio pro personae o pro homine implica que en caso de que haya dos o más normas aplicables — sean éstas nacionales o internacionales - a un caso concreto, el juzgador deberá optar por aplicar las que brinden mayor protección a los derechos humanos de los involucrados.

Al respecto, la Suprema Corte de Justicia de la Nación ha manifestado que:

Si en los instrumentos internacionales existe una protección más benéfica para la persona respecto de la institución jurídica analizada, ésta se aplique, sin que tal circunstancia signifique que, al ejercer tal función jurisdiccional, dejen de observarse diversos principios constitucionales y legales - legalidad, igualdad, seguridad jurídica, debido proceso, acceso efectivo a la justicia, cosa juzgada - o las restricciones que prevé la norma fundamental, ya que de hacerlo, se provocaría un estado de incertidumbre en los destinatarios de tal función. ${ }^{21}$

El cambio de paradigma que introdujo la reforma constitucional del 11 de junio de 2011, en materia de derechos humanos, impacta no sólo la interpretación del derecho en los casos concretos, sino la forma en que los servidores públicos despliegan sus actividades. No basta con que las autoridades ciñan su actuación a la norma, tienen la obligación de promover, respetar, proteger y garantizar los derechos humanos de conformidad con los principios de universalidad, interdependencia, indivisibilidad y progresividad, así como de prevenir, investigar, sancionar y reparar las violaciones a los derechos humanos - de acuerdo con su ámbito de competencia-en tanto que como servidores públicos forman parte del sistema institucional del Estado.

Conforme a lo anterior, y en congruencia con los compromisos internacionales que el Estado mexicano ha suscrito en materia de derechos humanos, y asimilados en la Constitución Política de los Estados Unidos Mexicanos, se publicó el 9 de enero de 2013 la Ley General de Víctimas. ${ }^{22}$

20 Tesis 1a. CCCLI/2014, Semanario Judicial de la Federación, Décima Época, 24 de octubre de 2014, libro II, t. I, p. 615.

21 Jurisprudencia 2aI/J. 56/2012, Semanario Judicial de la Federación y su Gaceta, Décima Época, libro 6, t. II, mayo de 2014, p. 772.

22 "Para atender a la obligación constitucional de todos los poderes y los órdenes de gobierno que integran el Estado mexicano del respeto, protección y promoción de los 
En la exposición de motivos de dicha Ley se menciona que la iniciativa constituye una respuesta a la demanda de "visibilidad, dignificación y reconocimiento de los derechos de las víctimas del delito y de violaciones de derechos humanos", así como al reconocimiento de las obligaciones del Estado mexicano para la atención a las víctimas; obligaciones no sólo para promover la ayuda, atención y reparación integral a la víctima, sino que además garanticen la no repetición de los actos victimizantes, y eviten la criminalización y victimización secundaria de los afectados. ${ }^{23}$

Asimismo, en la iniciativa de la Ley General de Víctimas se reconoce como indispensable que dicha ley coordine los mecanismos y medidas necesarias para "promover, respetar, proteger, garantizar y permitir el ejercicio efectivo de los derechos de las víctimas, mediante la vinculación de todas las autoridades en el ámbito de sus distintas competencias". ${ }^{24}$

Al respecto, se determinó que esta ley, reglamentaria de los artículos 1o., 17 y 20 constitucionales, fuera de observancia obligatoria en todo el territorio nacional, y para los tres ámbitos de gobierno: federal, estatal y municipal. ${ }^{25}$

Esta ley crea el Sistema Nacional de Atención a Víctimas, operado por la Comisión Ejecutiva de Atención a Víctimas, órgano descentralizado que permitirá al Estado brindar una reparación integral —a quienes acrediten la calidad de víctima como consecuencia de la comisión de un delito o por violaciones a sus derechos humanos - mediante cinco tipos de medidas, congruentes con los criterios de la Corte Interamericana de Derechos Humanos, respecto al daño y su forma de reparación: restitución, rehabilitación, compensación, satisfacción y no repetición. ${ }^{26}$

derechos humanos y como un fundamento axiológico que parte del reconocimiento pleno de los derechos humanos de las personas y de la atención a las víctimas como sujetos titulares de esos derechos, se presenta esta iniciativa de Ley General de Víctimas...", Iniciativa con Proyecto de Decreto por el que se Expide la Ley General de Víctimas, Diario 23, Gaceta 378, 17 de abril de 201, segundo periodo ordinario, LXI Legislatura de la Cámara de Senadores.

23 Idem.

24 Idem.

25 “A través de esta propuesta de ley se pretende garantizar que las víctimas no sólo de delito sino también de violaciones a los derechos humanos, sean respetadas en su esfera de derechos tanto reconocidos por la Constitución, como por la normatividad internacional en la materia. Es sumamente relevante para este proyecto de ley que el Estado garantice el restablecimiento de la víctima en el ejercicio pleno de sus derechos, y que promueva la superación de su condición....”, idem.

26 Para la Corte Interamericana, el daño material supone la "pérdida o detrimento de 
- Restitución: busca devolver a la víctima a la situación anterior a la comisión del delito o la violación de sus derechos humanos;

- Rehabilitación: busca facilitar a la víctima hacer frente a los efectos sufridos por causa del hecho punible o de las violaciones de derechos humanos;

- Compensación: se otorgará por todos los perjuicios, sufrimientos y pérdidas económicamente evaluables que sean consecuencia del delito o de la violación de derechos humanos, incluyendo el error judicial ${ }^{27}$

- Satisfacción: busca reconocer y restablecer la dignidad de las víctimas;

- Las medidas de no repetición: buscan que el hecho punible o la violación de derechos sufrida por la víctima no vuelva a ocurrir. ${ }^{28}$

De las cinco medidas enunciadas, la compensación — que es la medida que mayor semejanza guarda con respecto a la indemnización a que hace referencia la Ley Federal de Responsabilidad Patrimonial del Estado- incluye: la reparación del daño sufrido a la integridad de la víctima; el daño moral; el resarcimiento de los perjuicios causados o lucro cesante; los daños patrimoniales generados como consecuencia de delitos o violaciones a derechos humanos; el pago de gastos y costas judiciales y de los tratamientos médicos o terapéuticos necesarios para la recuperación de la salud psíquica y física de la víctima; y en su caso, los gastos comprobables de transporte, alojamiento, comunicación y alimentación que le ocasione a la víctima trasladarse al lugar del juicio o asistir a un tratamiento cuando su lugar de

los ingresos de las víctimas, los gastos efectuados con motivo de los hechos y las consecuencias de carácter pecuniario que tengan un nexo causal con los hechos del caso"; mientras que el daño inmaterial comprende los sufrimientos y las aflicciones causados a la víctima directa y a sus allegados, el menoscabo de valores muy significativos para las personas, y las alteraciones, de carácter no pecuniario, en las condiciones de existencia de la víctima o su familia. Corte Interamericana de Derechos Humanos, caso de los "Niños de la calle" (Villagrán Morales y otros) vs. Guatemala. Reparaciones y costas, serie C, núm. 77, sentencia de 26 de mayo de 2001, párr. 84.

27 Habrá de otorgarse a la víctima de forma apropiada y proporcional a la gravedad del hecho punible cometido o de la violación de derechos humanos sufrida y teniendo en cuenta las circunstancias de cada caso, de acuerdo con el artículo 27 de la Ley General de Víctimas, Diario Oficial de la Federación, 9 de enero de 2013.

28 Artículos 9o., 27, 61, 73 y 74 de la Ley General de Víctimas. 
residencia esté fuera del lugar del juicio, y cuyo importe no podrá ser mayor al veinticinco por ciento del monto total reclamado. ${ }^{29}$

La Ley General de Víctimas prevé que los interesados primero demuestren que han sufrido alguno de los daños a que se refiere la ley - daño o menoscabo económico, físico, mental o emocional, así como por cualquier riesgo o lesión de bienes jurídicos o derechos a consecuencia de la comisión de un delito o violaciones de los derechos humanos reconocidos en la Constitución y en los tratados internacionales de los que México es partepara que después, y conforme a las circunstancias del caso, se determine el monto de la compensación correspondiente, y en su caso, otras medidas de reparación adicionales. ${ }^{30}$

Como se puede advertir, la "reparación integral" prevista en la Ley General de Víctimas incorpora mecanismos adicionales a la "reparación integral del daño" descrita en el artículo 12 de la Ley Federal de Responsabilidad Patrimonial del Estado, en atención de la naturaleza de los bienes jurídicos que son vulnerados con la comisión de un delito o la violación de derechos humanos, los cuales difieren de los daños materiales, personales y morales a que hace referencia la ley reglamentaria del párrafo segundo del artículo 113 constitucional, que a partir de la reforma de mayo de 2015, que dio vida al Sistema Nacional Anticorrupción, se incorporó en el último párrafo del artículo 109 de la Constitución.

En este contexto, es importante destacar que la Primera Sala de la Suprema Corte de Justicia de la Nación emitió la tesis 1a. CLXII/2014 (10a.), la cual deriva de la ejecutoria del veintidós de noviembre de dos mil trece, dictada en el amparo directo en revisión 2131/2013, y que a la letra expone:

DERECHOS A UNA REPARACIÓN INTEGRAL Y A UNA JUSTA INDEMNIZACIÓN POR PARTE DEL ESTADO. SU RELACIÓN Y ALCANCE.

El artículo 113, párrafo segundo, de la Constitución Política de los Estados Unidos Mexicanos reconoce el derecho de los particulares a obtener una indemnización en caso de que el Estado, a través de sus servidores

29 Es importante destacar que la orden de compensación sólo puede establecerse por mandato judicial o por acuerdo de la Comisión Ejecutiva.

30 Los órganos jurisdiccionales nacionales, los organismos públicos de derechos humanos también nacionales, los órganos jurisdiccionales internacionales o los organismos públicos internacionales de derechos humanos, reconocidos por los tratados internacionales ratificados por México, serán quienes determinen, en las resoluciones que emitan, según sea el caso, los términos y monto de la compensación conducente. 
públicos, cause un daño en su patrimonio, sea en el plano material o inmaterial, con motivo de su actividad administrativa irregular, mientras el párrafo tercero del artículo 1o. constitucional prevé la obligación del Estado de reparar las violaciones a los derechos humanos. De acuerdo con lo anterior, quienes prueben haber sido dañados en su patrimonio con motivo de una actividad administrativa irregular del Estado, deberán acreditar que ésta constituyó una violación a un derecho o a diversos derechos humanos contenidos en la Constitución o en los tratados internacionales de los que el Estado Mexicano sea parte, para poder ser "reparadas integralmente" y, en algunos casos, el estándar de "reparación integral" podrá alcanzarse mediante una indemnización, como lo prevé el párrafo segundo del artículo 113 constitucional, siempre y cuando no pueda restablecerse a la persona afectada a la situación en que se encontraba antes de la violación y la medida indemnizatoria o compensatoria sea suficiente para considerarla "justa". Sin embargo, si en otros casos la indemnización fuera insuficiente para alcanzar el estándar de "reparación integral", las autoridades competentes deben garantizar medidas adicionales - como lo son las de satisfacción, rehabilitación o las garantías de no repetición— que sean necesarias y suficientes para reparar integralmente a las personas por los daños materiales o inmateriales derivados de la actividad administrativa irregular del Estado que impliquen violaciones a sus derechos humanos, en términos del párrafo tercero del artículo 1o. constitucional. ${ }^{31}$

Al respecto, no se comparte el criterio de Primera Sala de la Corte, en virtud de que, como se ha dicho antes, la indemnización prevista en el segundo párrafo del artículo 113 constitucional no surgió como mecanismo de reparación para los casos en que el Estado viole derechos humanos, sino para reparar los daños materiales, personales y morales generados a los particulares por la actividad administrativa irregular del Estado.

En función de lo anterior, los sistemas de responsabilidad a cargo del Estado: el previsto en la Ley General de Víctimas, y el analizado, regulado en la Ley Federal de Responsabilidad Patrimonial del Estado, no poseen el mismo origen teleológico, es decir, no surgieron para reparar violaciones a los derechos humanos, y por tanto, no necesitaban de la interpretación sistemática entre los artículos 1o. y 133 constitucionales que hizo el alto tribunal.

Sin duda, dicha Sala omitió considerar que la Ley General de Víctimas es reglamentaria del artículo 1o. constitucional. Lo anterior se complica

31 Tesis CLXII/2014, Semanario Judicial de la Federación, Décima Época, 25 de abril de 2014. 
aún más si se considera que la Sala Superior del Tribunal Federal de Justicia Fiscal y Administrativa ha aplicado el régimen de responsabilidad patrimonial del Estado para abordar lesiones a derechos humanos, en los casos en los cuales se ha imputado al Ministerio Público la comisión de la actividad irregular. ${ }^{32}$

No obstante, para dicha Sala el mecanismo de responsabilidad, previsto en el artículo 113 constitucional, permite reparar violaciones de derechos humanos, atendiendo a la "magnitud de la violación", la cual se determina en función de los daños o perjuicios generados por la actividad administrativa irregular del Estado, lo cual permite formular la interrogante siguiente: ¿qué implicaciones tiene que, en aplicación de la normatividad de la responsabilidad patrimonial del Estado, se indemnice a un particular por lesiones en materia de derechos humanos?

Se advierten como posibles respuestas: 1) esa indemnización excluye las reparaciones económicas previstas en la Ley General de Víctimas, 2) esa indemnización complementa la compensación prevista en la Ley General de Víctimas, o 3) son sistemas autónomos que pueden convergir, con la consecuencia de que el particular obtenga dos indemnizaciones por violaciones de derechos humanos.

Ahora bien, es posible respaldar cada una de las posibles respuestas, sin embargo, si los tribunales no solucionan correctamente esta problemática, los particulares pueden obtener indemnizaciones mayores a las cuales tienen derecho en perjuicio de las finanzas públicas.

Es claro, no se pretende afirmar que una vez ejercido alguno de los sistemas, tenga por consecuencia que sea improcedente procesalmente hablando el otro sistema; esto es, se estima que si el particular ejerce la vía de la Ley General de Víctimas, ello no hace improcedente la vía de la Ley Federal de Responsabilidad Patrimonial del Estado, lo que se plantea es una cuestión sustancial referida a cómo deben los tribunales resolver un juicio en el cual la litis verse sobre la indemnización por violación de derechos humanos, si el solicitante ya obtuvo una reparación económica en otro sistema de responsabilidad por la misma violación de derechos humanos.

Por otra parte, como se ha dicho en este trabajo, también se pueden entender ambos sistemas como complementarios. Porque si bien todo daño causado a un particular se puede extrapolar a un derecho humano, no toda 
actividad del Estado tiene como consecuencia que el particular reciba una "reparación integral" conforme al tercer párrafo del artículo 1o. constitucional — por violaciones a derechos humanos-, es decir, en términos de la Ley General de Víctimas, sino que bastaría una reparación integral del daño, conforme al artículo 112 de la Ley Federal de Responsabilidad Patrimonial del Estado, mediante una indemnización.

Toda violación a los derechos humanos es grave, y debe ser reparada, en caso de que el tipo violación y el derecho humano de que se trate ameriten una justa indemnización, pero, no puede ser un medio para obtener reparaciones económicas ilimitadas si ya fue satisfecha económicamente por el Estado mediante las medidas de reparación otorgadas en otro mecanismo de responsabilidad.

\section{CONCLUSIONES}

1. El segundo párrafo del artículo 113 de la Constitución prevé que la responsabilidad patrimonial del Estado será "objetiva y directa", sin embargo, al restringir la procedencia del otorgamiento de la indemnización sólo para aquellos casos en que los daños se hayan generado por la "actividad administrativa irregular del Estado" — en los hechos-, ésta deja de ser objetiva para convertirse en una acción, que si bien ya no requiere personalizar o subjetivar al agente causante del daño servidor público - aun la identificación, sí desnaturaliza el propósito de la responsabilidad objetiva y directa.

2. El régimen de responsabilidad del Estado, previsto en la Ley General de Víctimas, surgido casi una década después del segundo párrafo del artículo 113 constitucional — producto de los reclamos de la sociedad civil en materia de seguridad pública, atención a las víctimas del delito y de violaciones a los derechos humanos-, busca que el Estado cumpla con su obligación de adoptar las medidas necesarias — como lo exige el artículo 1o. constitucional- para promover, respetar, proteger y garantizar los derechos humanos, así como para prevenir, investigar, sancionar y reparar las violaciones de éstos.

3. La ambigüedad en la redacción del párrafo segundo del artículo 113 - y no resuelta en su ley reglamentaria ni con las tesis de las Suprema Corte - ha ocasionado que los particulares acudan al Tribunal Federal de Justicia Fiscal y Administrativa a promover acciones a la luz de 
la doctrina de la responsabilidad patrimonial del Estado, conforme al segundo párrafo del artículo 113 constitucional, para abordar lesiones a derechos humanos, lo cual puede ocasionar que un particular obtenga dos indemnizaciones por violación a sus derechos humanos, con el consecuente ejercicio ineficiente de los recursos públicos, porque en ambos, es el Estado quien repara la lesión.

4. De igual forma, cuando los particulares acuden, al amparo del artículo 113 constitucional y su ley reglamentaria, a solicitar una indemnización por violaciones de derechos humanos — por las restricciones de la legislación base de la acción - no siempre es posible establecer el vínculo causal entre la conducta del Estado que se presume "irregular" y los daños reclamados, porque, en términos de los artículos 18 a 21 y 23 de la Ley Federal de Responsabilidad Patrimonial del Estado, y 50 A de la Ley Federal del Procedimiento Contencioso Administrativo, en muchas ocasiones, los daños son consecuencia de otros actos de distinta naturaleza, como cuando se trata de privación de la libertad por prisión preventiva injusta, la cual es competencia del Poder Judicial. ${ }^{33}$

5. Es deber de los juristas construir una teoría integral de la responsabilidad patrimonial del Estado, pues no se dispone de conceptos adecuados y unívocos para definir: i) esfera administrativa; ii) actividad administrativa lesiva con y sin causa, y iii) alcances de: a) la obligación de disponer de suficiencia presupuestal ante contingencias relativas a la reparación integral para la administración pública, b) derechos conculcados objetos de reparación por la aplicación de una ley, c) catálogo de consecuencias derivadas de un acto del gobierno susceptibles de reparación, d) dimensión pecuniaria de una compensación satisfactoria,

33 Respecto a la importancia de destacar el nexo causal entre los daños reclamados y la actividad administrativa irregular, el Primer Tribunal Colegiado en Materia Administrativa del Primer Circuito, quien mediante tesis aislada ha manifestado que de acuerdo con el artículo 22 de la Ley Federal de Responsabilidad Patrimonial del Estado, los elementos que debe demostrar la parte reclamante son (el subrayado es propio): la existencia del daño en su patrimonio y el nexo causal entre éste y la actividad del Estado, son elementos sustantivos que deben colmarse para que se dicte una resolución favorable, ya que aun cuando, en algunos casos, el tema relativo a la titularidad sobre un bien envuelve un aspecto de legitimación y, por ende, un presupuesto para dar trámite al procedimiento, en la hipótesis de que se trata ese tópico constituye un requisito para que se reconozca el derecho pretendido, toda vez que no se justificaría resarcir un daño que no recayó en el patrimonio de quien pretende la indemnización. Tesis: I.1o.A.63 A, Semanario Judicial de la Federación, Décima Época, 25 de abril de 2014. 
como resultado de una indemnización, e) restitución, f) rehabilitación, g) daño simbólico y h) acciones transformadoras, entre otras.

6. La sociedad mexicana cada vez presta mayor atención a la actuación del Estado, y con ello, a las formas que el mismo brinda para responder por los daños que cause a los particulares. En este contexto, clarificar los alcances de los sistemas de reparación previstos en la Ley General de Víctimas y en la Ley Federal de Responsabilidad Patrimonial del Estado, y analizados en las líneas anteriores, es una labor indispensable para promover la consolidación de la responsabilidad patrimonial del Estado. 